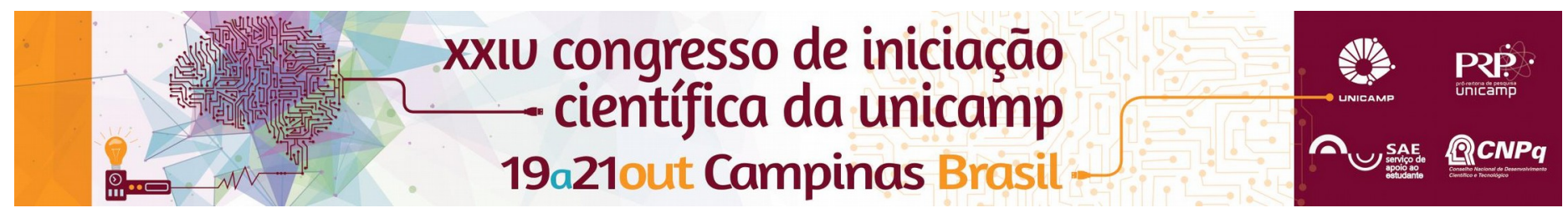

\title{
Método de Otimização Híbrido Aplicado ao Processo de Ajuste de Histórico Assistido
}

\section{Leonardo N. Parmigiani*, Denis J. Schiozer, Célio Maschio}

\section{Resumo}

A simulação numérica de reservatórios é uma importante área da engenharia de petróleo que visa modelar o comportamento de reservatórios durante a produção. $O$ foco da pesquisa "Método de Otimização Hibrido Aplicado ao Processo de Ajuste de Histórico Assistido" é a aplicação de um método híbrido e adaptativo de otimização ao problema de ajuste de histórico, que é responsável por calibrar modelos numéricos de campos de petróleo através da redução da diferença entre os dados do histórico e os dados simulados.

Palavras-chave:

Ajuste de histórico; simulação numérica; otimização

\section{Introdução}

O ajuste de histórico é um processo complexo devido ao grande número de incertezas envolvidas na caracterização do reservatório e trata de um problema inverso com muitos parâmetros onde a saída é conhecida (o histórico de produção) e os dados de entrada não são conhecidos (SOUSA, 2007). Outra dificuldade presente no processo é atribuída à existência de mais de uma solução (SANTOS e SCHIOZER, 2000). O objetivo do projeto é a aplicação do método híbrido e adaptativo de otimização ao problema de ajuste de histórico. Para que esta metodologia seja validada, utiliza-se um modelo sintético de reservatório UNISIM-I$\mathrm{H}$ (Figura 1), cujos dados resposta conhecida, permitindo uma melhor avaliação do método de otimização proposto.

\section{Metodologia}

As ferramentas computacionais utilizadas para 0 desenvolvimento do ajuste de histórico foram: IMEX, simulador de fluxo de diferenças finitas e o MERO, desenvolvido pelo Grupo de Pesquisa em Simulação e Gerenciamento de Reservatórios. Este último permitiu a execução de todas as ferramentas necessárias, entre elas a mais importante, o método de busca direta Hooke\&Jeeves, o qual utiliza um algoritmo de busca direta, que trabalha sobre um espaço de busca formado pela discretização dos atributos de ajuste.

$\mathrm{O}$ projeto foi baseado na melhora dos ajustes dos poços do caso supracitado, entre elas estão: vazão de água, óleo, gás, líquido e a pressão.

\section{Aplicação}

O modelo UNISIM-I-H é baseado no modelo geológico do Campo de Namorado, localizado na Bacia de Campos, Brasil.

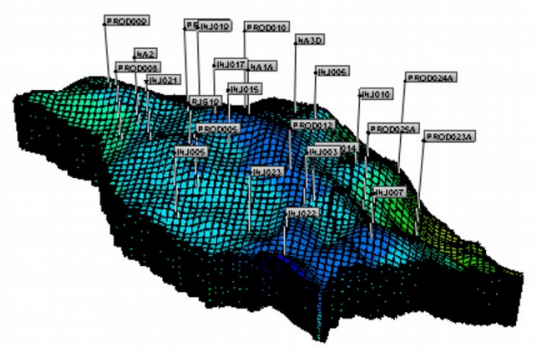

Figura 1. Modelo de simulação UNISIM-I-H
Como validação da metodologia, 500 pontos foram gerados, os quais passaram por diversas buscas locais pelo método Hooke\&Jeeves. Assim restaram 10 pontos selecionados que tiveram as propriedades otimizadas, aproximando assim do caso base (histórico).

\section{Resultados e Discussão}

A Figura 2 mostra os resultados da otimização da vazão de água por meio do método Hooke\&Jeeves, onde o AQNS (afastamento quadrático normalizado com sinal) é usado como indicador de qualidade de ajuste

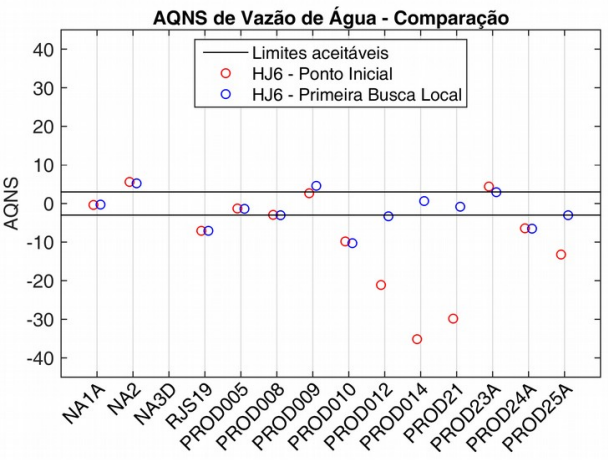

Figura 2. Indicador de ajuste na vazão de água (QW)

Podemos notar uma aproximação dos pontos à faixa de aceitação com o avanço da busca local. Esse ajuste pode ser considerado bom por conta da maioria dos poços estarem dentro do valor de aceitação (faixa do gráfico).

\section{Conclusão}

Analisando os resultados é possível concluir que os ajustes referentes as propriedades dos poços apresentam-se adequados, portanto a etapa de refinamento aumentou a qualidade do ajuste. Uma forma de melhorar mais o ajuste é através de um maior número de iterações e mais etapas de refinamento durante 0 processo de ajuste de histórico.

SOUSA, S. H. G. Aplicação da Metaheurística Busca Dispersa ao Problema de Ajuste de Histórico. Dissertação de Mestrado (Mestre em Ciências e Engenharia de Petróleo) - Universidade Estadual de Campinas, 2007.

SANTOS, J. P.; SCHIOZER, D. J. Automatic History Matching of an Offshore Field in Brazil. Rio Oil \& Gas Conference, Rio de Janeiro, 2000. 